\title{
Emergency department visits for children with acute asthma: discharge instructions, parental plans, and follow-through of care-a prospective study
}

\author{
Pat G. Camp, PT, PhD*; Seamus P. Norton, MD; Ran D. Goldman, MD ${ }^{\S}$; ; Salomeh Shajari, BSc ${ }^{\top}$; \\ M. Anne Smith, BSc (Pharm), MS ; Susan Heathcote, RN ${ }^{\#}$; Bruce Carleton, PharmD ${ }^{\|}$
}

\section{ABSTRACT}

Objective: Communication between emergency department (ED) staff and parents of children with asthma may play a role in asthma exacerbation management. We investigated the extent to which parents of children with asthma implement recommendations provided by the ED staff.

Method: We asked questions on asthma triggers, ED care (including education and discharge recommendations), and asthma management strategies used at home shortly after the ED visit and again at 6 months.

Results: A total of 148 children with asthma were recruited. Thirty-two percent of children were not on inhaled corticosteroids prior to their ED visit. Eighty percent of parents identified upper respiratory tract infections (URTIs) as the primary trigger for their child's asthma. No parent received or implemented any specific asthma strategies to reduce the impact of URTIs; $82 \%$ of parents did not receive any printed asthma education materials. Most (66\%) parents received verbal instructions on how to manage their child's future asthma exacerbations. Of those, one-third of families were told to return to the ED. Parents were rarely advised to bring their child to their family doctor in the event of a future exacerbation. At 6 months, parents continued to use the ED services for asthma exacerbations in their children, despite reporting feeling confident in managing their child's asthma.

Conclusion: Improvements are urgently needed in developing strategies to manage pediatric asthma exacerbations related to URTIs, communication with parents at discharge in acute care, and using alternate acute care services for parents who continue to rely on EDs for the initial care of mild asthma exacerbations.
RÉSUMÉ

Objectif: Les communications entre le personnel des services d'urgence (SU) et les parents d'enfants asthmatiques peuvent jouer un rôle dans le traitement des crises d'asthme. L'étude visait à vérifier dans quelle mesure les parents concernés appliquaient les recommandations données par le personnel des SU.

Méthode: Nous avons posé des questions aux parents sur les facteurs déclencheurs des crises d'asthme, les soins reçus au $\mathrm{SU}$ (y compris l'enseignement et les recommandations faites au moment du congé), et les stratégies de traitement de I'asthme appliquées à domicile, peu de temps après la consultation au SU, puis au bout de 6 mois.

Résultats: Au total, 148 enfants asthmatiques ont été sélectionnés. Trente-deux pour cent des enfants n'étaient pas traités par les corticostéroïdes en inhalation avant la consultation au SU, et $80 \%$ des parents ont indiqué une infection des voies respiratoires supérieures (IVRS) comme principal facteur déclencheur des crises d'asthme chez leur enfant. Aucun parent n'a reçu d'instructions particulières sur des stratégies visant à atténuer l'incidence des IVRS sur I'asthme, ou n'a appliqué de stratégie en ce sens; $82 \%$ des parents ont déclaré ne pas avoir reçu de matériel didactique écrit. La plupart des parents (66\%) ont reçu des instructions verbales sur la manière de traiter les futures exacerbations d'asthme chez leur enfant. À un tiers d'entre eux, on a dit de se présenter de nouveau au SU; rarement a-t-on conseillé aux parents d'aller consulter leur médecin de famille en cas de future exacerbation. Au bout de 6 mois, les parents continuaient à utiliser les services d'urgence pour les crises d'asthme chez leur enfant, et ce, malgré le sentiment avoué de confiance en leur capacité de traiter la maladie.

From the *James Hogg Research Centre, University of British Columbia, Vancouver, BC; †Department of Physical Therapy, University of British Columbia, Vancouver, BC; $\neq$ Department of Pediatrics, McMaster University, Hamilton, ON; §Division of Pediatric Emergency Medicine, Department of Pediatrics, University of British Columbia, BC Children's Hospital, Vancouver, BC; ॥Department of Pediatrics, University of British Columbia, Vancouver, BC; $\uparrow$ Pharmaceutical Outcomes Programme, Child \& Family Research Institute; Vancouver, BC; and \#Quality and Risk Management, BC Children's Hospital, Vancouver, BC.

Correspondence to: Dr. Bruce Carleton, Pharmaceutical Outcomes Programme, BC Children's Hospital, A3-212, 950 West 28th Avenue, Vancouver, BC V5Z 4H4; bcarleton@popi.ubc.ca.

This article has been peer reviewed. 
Conclusions: II faut élaborer sans tarder des stratégies de traitement des exacerbations d'asthme chez les enfants liées à des IVRS et de communication avec les parents au moment du congé du service des soins actifs, en plus de proposer des solutions de rechange aux parents qui continuent de se rendre au SU pour le traitement initial des crises d'asthme légères.

Keywords: asthma, exacerbation, pediatric
Asthma exacerbations are common in children and frequently result in visits to pediatric or general emergency departments (EDs). ${ }^{1}$ A recent populationbased study from Ontario noted that nearly $10 \%$ of children with asthma visit the ED at least once every 2 years, with most visits for exacerbations of high acuity. ${ }^{2}$ In the United States in 2004, childhood asthma accounted for 640,000 ED visits. ${ }^{3}$

Previous research examining predictors of ED visits for asthma focused on patients' socioeconomic, demographic, and physiologic factors associated with such visits. ${ }^{4-7}$ These studies identified multiple risk factors for pediatric asthma ED visits and subsequent relapses, including asthma severity, underuse of inhaled corticosteroids, overuse of beta-agonist monotherapy, ${ }^{4,8}$ increased age, ${ }^{8}$ passive smoke exposure ${ }^{8}$ and other environmental pollutants, ${ }^{6}$ and ED visits in the previous year. ${ }^{4,8}$

The National Asthma Education and Prevention Program (NAEPP) recommends follow-up care to reduce the risk of relapse. ${ }^{7}$ Follow-up with primary care providers after an ED visit is suboptimal. ${ }^{9-12}$ Communicating asthma severity to parents in the ED may improve such rates. ${ }^{13}$ In a study of EDs in Ontario, several ED strategies were associated with a reduction in return visits for asthma exacerbations, including the preprinted order forms, consulting a pediatrician during the ED visit, and following clinical practice guidelines.2 Similarly, we showed that implementation of an ED pediatric asthma clinical pathway, which used evidence-based guidelines and structured teaching, reduced hospitalization and return ED visits for asthma. ${ }^{14}$

These studies focused on broad systems of care to improve management of children with an asthma exacerbation. Less is known about the role of communication between ED staff and parents at the point of care and the impact of communication on the subsequent decisions of parents caring for the child. Educational sessions for parents and children with asthma following ED visits can improve health outcomes and enhance self- or parental care of asthma ${ }^{15}$ but communication that occurs during an ED visit could also impact future care decisions. Our objectives were to determine 1) the extent to which parents of children with asthma who receive ED services for acute asthma exacerbation recall and implement recommendations provided by ED staff; 2) the strategies used by these parents to manage and reduce the risk of future exacerbations; and 3) the pattern of use of health services of these children following ED visits.

\section{METHODS}

\section{Design and setting}

We conducted a prospective study of children with asthma who visited a pediatric ED for exacerbations of asthma. We interviewed their parents within 2 weeks of the child's ED discharge and again 6 months after the ED visit. This study was conducted at BC Children's Hospital (BCCH) in Vancouver, British Columbia, a 200-bed tertiary care pediatric hospital. Each year, the ED at BCCH treats approximately 2,000 children for asthma. Ethical approval for this study was obtained from the University of British Columbia Behavioural Research Ethics Board.

\section{Subject recruitment}

We recruited children with a previous diagnosis of asthma who visited the ED for an asthma exacerbation and were 0.5 to 15 years of age. Patients were excluded if their English skills were not sufficient to answer questions or provide informed consent; if their primary diagnosis in the ED was upper respiratory tract infection (URTI), lower respiratory tract infection, or pneumonia; or if their index ED visit resulted in a hospital admission.

\section{Emergency management and chart review}

Each child admitted to the ED received treatment for asthma in the ED according to the BCCH Emergency Management of Asthma Clinical Pathway, ${ }^{14}$ which included structured assessment/documentation forms, 
a plan-of-care flowchart designating therapy, and nursing and physician actions in the ED based on the severity of exacerbation. On arrival at the ED, the triage nurse categorized the asthma severity for each patient (Table 1). Patients who were categorized as "critical" exited the pathway and were not eligible for this study. Using the clinical pathway (Figure 1), children were treated according to their asthma severity. All patients received salbutamol, and children with moderate or severe exacerbations received ipratropium bromide and oral corticosteroids, as specified in the pathway. Patients meeting the criteria for discharge were provided with prescriptions and use instructions for salbutamol, oral corticosteroids, and inhaled corticosteroids. The clinical pathway contained a standardized printed checklist of education on asthma management, including the recommendation to follow up with the child's primary care physician within 48 hours of the ED visit. Teaching topics included anatomy and physiology, triggers, medications, inhaler technique, and signs and symptoms of respiratory distress. Physicians were trained in the use of the clinical pathway and checklist; however, they were not directly observed in their interactions with families.

\section{Telephone interviews}

Following discharge from the ED, we conducted telephone interviews with the parents of recruited children 7 to 14 days after their index visit. Using a pilot-tested structured questionnaire (Table 2), we collected information regarding asthma history, typical symptoms, medications, burden of asthma on the child and parents, previous ED visits and hospitalizations, sleeping patterns, and common triggers for the child's asthma exacerbations. We asked questions regarding the teaching that the parents received from ED staff at the time of their visit, including the purpose of each medication, indications and administration technique for each medication, any changes in therapy recommended by the ED staff, and instructions on how the parents should manage the next exacerbation. We further inquired about plans for ongoing asthma management, difficulties the children and parents encountered in managing asthma symptoms, level of confidence in managing asthma, and whether recommendations for medical follow-up were implemented.

At 6 months, the patients and families were contacted for a second interview. In this interview, participants were questioned regarding $\mathrm{ED}$ visits and hospitalizations in the 6 months following the index ED visit, any changes made to the asthma care plan since the first interview, and the level of confidence in managing their child's asthma.

\section{Statistical analysis}

Patient characteristics are reported as means and standard deviations or proportions, as appropriate. To determine whether our sample of patients was representative of the pediatric asthma population seen in the ED at BCCH during the study period, we compared the demographic features of enrolled children to those of children who previously visited the ED for asthma exacerbation and had a history of at least two episodes of wheeze, asthma-related symptoms, or a previous physician diagnosis of asthma in the 2 months preceding study initiation. To assess whether we had captured a sample of children comparable to our larger observed population, we compared patient characteristics of our sample to those

Table 1. Categorization of asthma severity by ED triage team

\begin{tabular}{|c|c|c|c|c|}
\hline & Mild & Moderate & Moderate/severe & Critical \\
\hline Accessory muscle use & $\begin{array}{l}\text { Minimal intercostal } \\
\text { retractions }\end{array}$ & $\begin{array}{l}\text { Intercostal and } \\
\text { substernal retractions }\end{array}$ & $\begin{array}{l}\text { Nasal flaring or suprasternal } \\
\text { retractions }\end{array}$ & $\begin{array}{l}\text { Nasal flaring/paradoxical } \\
\text { chest movement }\end{array}$ \\
\hline Wheeze & Minimal, end-expiratory & $\begin{array}{l}\text { Pan-expiratory } \pm \\
\text { inspiratory wheeze }\end{array}$ & $\begin{array}{l}\text { Wheeze audible without } \\
\text { stethoscope }\end{array}$ & $\begin{array}{l}\text { Silent breath sounds or } \\
\text { audible wheeze }\end{array}$ \\
\hline Dyspnea & $\begin{array}{l}\text { Minimal, normal } \\
\text { activity and speech }\end{array}$ & $\begin{array}{l}\text { Decreased activity, } 5 \text { - } \\
\text { to 8-word sentences }\end{array}$ & $\begin{array}{l}\text { Decreased activity, }<5 \text { word } \\
\text { sentences }\end{array}$ & $\begin{array}{l}\text { Unable to speak 1-to 2-word } \\
\text { sentences }\end{array}$ \\
\hline Peak flow & $\begin{array}{l}>70 \% \text { versus } \\
\text { personal best }\end{array}$ & $\begin{array}{l}51-70 \% \text { versus personal } \\
\text { best }\end{array}$ & $\begin{array}{l}41-50 \% \text { versus personal } \\
\text { best }\end{array}$ & $\begin{array}{l}\text { Peak flow } \leq 40 \% \text { of } \\
\text { personal best }\end{array}$ \\
\hline $\begin{array}{l}\text { Oxygen saturation } \\
\text { (on room air) }\end{array}$ & $>95 \%$ & $91-95 \%$ & $86-90 \%$ & $<86 \%$ \\
\hline
\end{tabular}




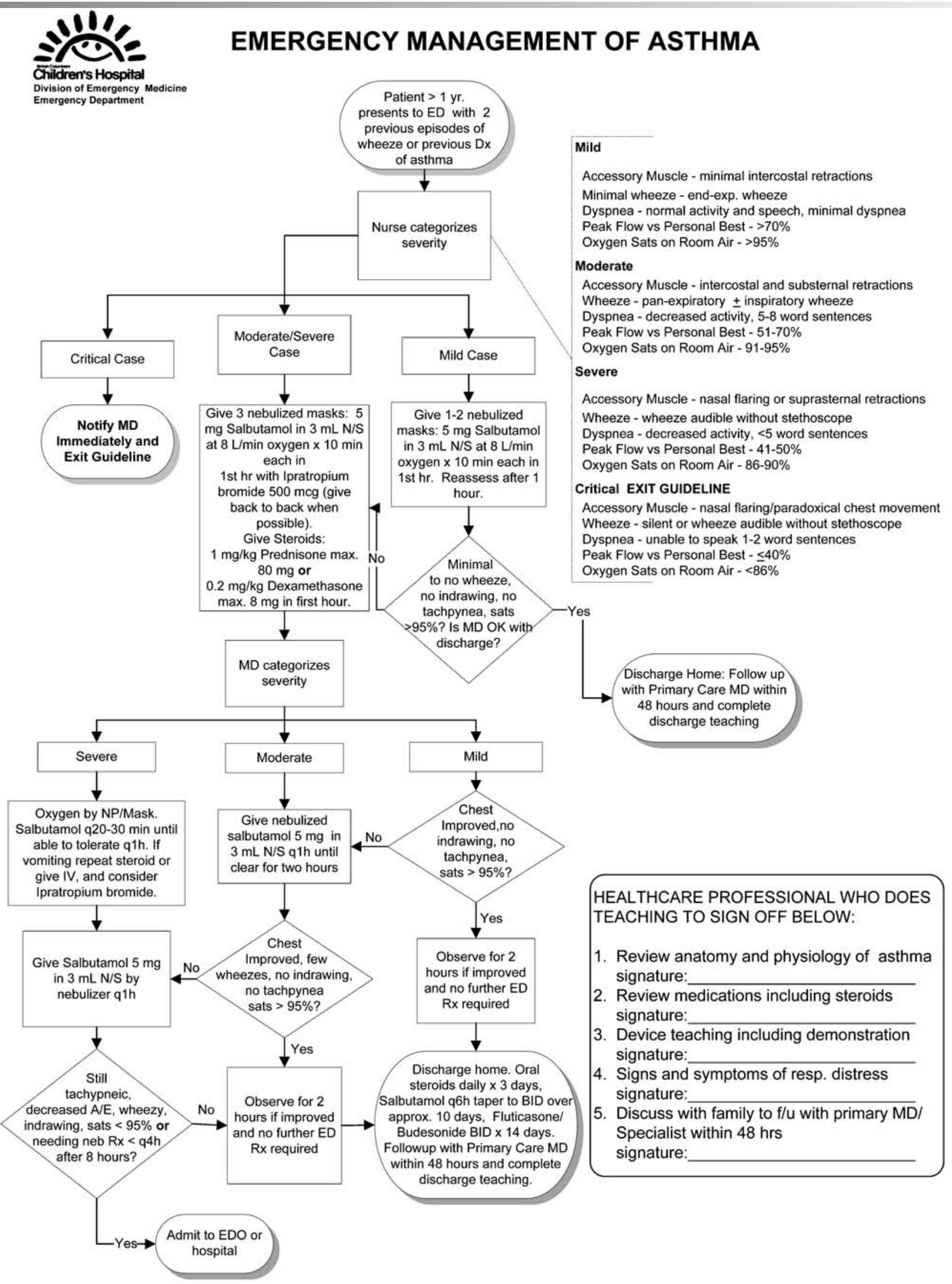

Figure 1. Clinical pathway for emergency management of pediatric asthma. $A / E=$ air entry; $D x=$ diagnosis; $E D=$ emergency department; $\mathrm{EDO}=$ emergency department observaxon unit; NP = nasal prongs; N/S = normal saline. 


\section{Table 2. Questions from interviewer-administered questionnaire}

Past history

1. How long has your child had asthma?
a. Less than 6 months
b. 6-11 months
c. 1-3 years
d. $4-5$ years
e. $>5$ years

2. How many times has your child been to an emergency department in the past year because of asthma?
a. 0
b. 1-2 times
c. 3-5 times
d. $>5$ times

3. Has your child been admitted to the hospital in the past year because of asthma? If yes, how many times?

Asthma symptoms while stable

4. Prior to the problem leading to your child's recent visit to the ED, how many months per year does your child typically have asthma symptoms?
a. 1-2 months
b. 3-5 months
c. $6-8$ months
d. 9-12 months

5. During a typical month when your child has asthma, how many days does your child have asthma symptoms?
a. $0-6$ days
b. 7-14 days
c. 15-21 days
d. $22+$ days

6. When your child has asthma symptoms, how many days in a month does he/she typically miss school, play, or extracurricular activities?
a. No days
b. $1-5$ days
c. $6-10$ days
d. 11-15 days
e. $>16$ days
f. Not applicable—child is too young

7. During a typical month when your child has asthma, how many times a week does your child awaken due to coughing or trouble breathing?
a. $<$ weekly
b. 1-3 times per week
c. 4 times per week
d. $>4$ times per week
e. Only when having an asthma attack

8. Do you know what triggers your child's asthma symptoms? (Check all applicable)
a. Exercise
b. URTI
c. Animals
d. Smoke
e. Stress/emotion
f. Environmental
g. Unknown
h. Other

Medication management

9. What medications are prescribed to your child to manage his/her asthma?

Recent asthma exacerbation and ED management

10. Asthma attacks are often triggered by something. Do you know what triggered the last attack that brought you to the ED on that day?

a. Yes-please list

b. No 


\section{Table 2. Continued}

11. What medications was your child on at the time of admission to the ED? Please list.

12. What new medications were prescribed to your child in the ED? Please list.

13. When you were in the ED, were you given instructions on asthma, such as how to use inhalers and other asthma devices?
a. Yes
b. No

If yes, were these instructions written, verbal, or both?

14. When you were in the emergency department, did anyone show you how to use the inhalers and other asthma devices?

a. Yes

b. No

15. When you were in the emergency department, did anyone tell you how your child's medications work to help control asthma?
a. Yes
b. No

16. Were you given any asthma-related reading materials to take home from the emergency department?
a. Yes
b. No

17. Were you given instructions on how to manage your next child's asthma attack? If yes, what were you told?
a. Come to the ED
b. See your GP/pediatrician
c. Increase or start your child's medication
d. Other

18. Were you referred to your family doctor, asthma specialist, or an asthma clinic? If yes, did you go to the appointment? If no, why not?

Home management

19. Do you feel confident enough to manage your child's asthma at home?
a. Yes
b. No

20. Have you made any, or do you plan to make, any changes to your child's home environment?
a. Plan to make changes
b. Have already made changes (please list)
c. Do not plan to make any changes

21. Do you have a family doctor or specialist to go to for future help related to your child's asthma?
a. Yes
b. No

$\mathrm{ED}=$ emergency department; $\mathrm{GP}=$ general practitioner; $\mathrm{URTI}=$ upper respiratory tract infection

of a separate random sample of $33 \%$ of all children with BCCH ED visits for asthma during the study months for each of the years 2000, 2001, and $2002(n=$ 224).

For each question or group of questions, the percentages of patients whose parents provided responses are reported. Chi-square analysis was used to assess the relationships between medication use, health care use, and sex. All analyses were conducted with $S A S$ version 9.1 (SAS Institute, Cary, NC).

\section{RESULTS}

\section{Patient characteristics}

One hundred sixty-four patients were prospectively recruited from the BCCH ED between April 2002 and
October 2003. All patients were recruited after ED visits for an exacerbation of their asthma. Ten individuals were subsequently excluded from further study as they were concurrently enrolled in a separate study on asthma care. Six additional families who had been initially recruited were not subsequently available for the first interview and were excluded. Among the remaining 148 subjects (Table 3), most were boys, and the mean age was 5.3 years (standard deviation 3.3 years, range $0.5-15$ years). One child less than 1 year old was inadvertently recruited, but inclusion of this child's data did not alter the study results.

There were no significant differences in sex, age distribution, asthma severity, and admission to hospital between our recruited patients and children randomly obtained from the hospital database $(p>0.05)$, indicating that our sample was similar to pediatric 
Table 3. Baseline characteristics of interview study patients and random sample of BCCH asthma patients admitted to the ED*

\begin{tabular}{lcc}
\hline & Study sample $(n=148)$ & Random sample of BCCH asthma ED patients $(n=224)$ \\
\hline Male (\%) & 66.2 & 60.5 \\
Age (yr) & 5.3 & 4.7 \\
$\quad$ Mean & 4.6 & 4.0 \\
$\quad$ Median & $0.5-14.9$ & $0-18$ \\
$\quad$ Age range & & 47.3 \\
Asthma severity based on ED Triage team (\%) & 35.8 & 37.9 \\
$\quad$ Mild & 46.4 & 13.2 \\
$\quad$ Moderate & 17.9 & 22.2 \\
$\quad$ Moderate-severe & 17.9 & \\
Admitted to hospital (\%) & & \\
\hline BCCH $=$ BC Children's Hospital; ED = emergency department. & & \\
${ }^{*} p$ values for all comparisons $>0.05$. & &
\end{tabular}

asthma patients who typically visit the BCCH ED (see Table 3).

\section{Burden of asthma and medication management}

Forty-four percent of parents reported their child having asthma for 1 to 3 years. Twenty-nine percent of the children had a diagnosis of asthma for more than 3 years. In general, these children regularly obtained asthma care from hospital services, $43 \%$ had been to the ED for an asthma exacerbation three or more times in the past year, and $35 \%$ had been admitted to hospital over the last year. There were no significant gender differences in previous medication use or previous $\mathrm{ED}$ visits.

The majority of the patients $(n=104 ; 70 \%)$ had at least 3 symptomatic months in a year, and in a typical symptomatic month, 41 children $(28 \%)$ had symptoms for at least 7 days. Of the 101 patients who attended school or other extracurricular activities, 61 children $(60 \%)$ missed at least 1 day and 13 children (13\%) missed at least 6 days per month due to asthma. Sleep was disrupted. During an asthma exacerbation, 84 children $(57 \%)$ woke up at least once a week due to asthma symptoms and 31 children (21\%) woke up at least four times per week.

Thirty-four children (23\%) were not using any asthmarelated medication prior to their index ED visit. Of the 114 children who were using asthma medications, 48 children (42\%) were not using inhaled corticosteroids.

\section{Characteristics of the index visit}

\section{Triggers}

With respect to triggers of the asthma exacerbation that led to their child's index visit to the ED, 119 families $(80 \%)$ reported that a URTI was the primary trigger of their child's exacerbation at the index visit. The parents of 10 children (7\%) identified environmental triggers such as dust, whereas 7 parents $(5 \%)$ identified exercise as the main trigger for their child. Remaining triggers reported were pet dander, smoke, and emotional stressors.

\section{Discharge treatments}

Fifty-one percent of parents reported that they had received a prescription for oral corticosteroids at discharge. Boys were more likely to be discharged with a prescription for oral corticosteroids compared to girls (odds ratio 3.50, 95\% confidence interval 1.70-7.20; $p<$ $0.0005)$. Whereas 62 children (42\%) had not been receiving inhaled corticosteroids at the time of the index visit, 36 children (24\%) remained without inhaled steroids at discharge from the ED, with no significant difference noted between girls and boys $(p=0.25)$.

\section{Instructions at discharge}

Most parents did not recall being given any information regarding their child's asthma medications or use of inhaler devices (Table 4). Furthermore, most parents $(82 \%)$ did not recall being provided with any asthma-related printed reading materials to review at home. Parents of 94 children (65\%) reported being instructed to have a follow-up appointment with their family doctor, specialist, or clinic physician after the index exacerbation.

With respect to the management of future exacerbations, 98 families (66\%) reported receiving verbal instructions from ED staff on how to manage their child's future episodes of acute asthma (Figure 2). Of those parents, 65 families $(66 \%)$ were instructed to 
Table 4. Parents' recall of education received from ED staff 2 weeks after index visit

Information/education at the ED

Parent self-report of receiving education in the ED $n(\%)$

Outlining specific symptoms to monitor that would indicate whether asthma medications are

$17(11.5)$

effective (i.e., nighttime coughing, ability to exercise, etc.)

Explaining how medication(s) work to help control asthma

Providing written instructions on how to use inhalers and other asthma devices

$E D=$ emergency department.

increase the frequency and/or dosage of inhaled medications, 26 families (27\%) were told to return to the ED, and 7 families (7\%) were told to see their family physician in the event of a future exacerbation.

\section{Parents' care decisions postdischarge}

Sixty-five percent of parents were instructed to visit their family doctor with their child for a follow-up appointment after the index visit. Of these, 29 parents $(30 \%)$ did not attend that appointment. The main reason for nonattendance was that they perceived their child to be well and the parents felt that a follow-up appointment was unnecessary. Other reasons for nonattendance were the inconvenience of a follow-up appointment and the absence of a primary care doctor.

At the first interview, $56 \%$ of parents planned to make or had already made changes to their child's home environment. Virtually all changes described by parents included reducing exposure to dust by replacing carpets with hardwood floors, changing bed covers and mattresses, removing stuffed animals, and increasing the frequency of dusting and vacuuming. Parents did not report any planned strategies to reduce the impact of URTIs on their child's asthma. No parents indicated that they would initiate or alter the child's regimen of treatment with corticosteroid medication at the onset of symptoms of URTI.

\section{Parental confidence in managing future exacerbations}

Eighty percent of parents reported feeling confident to manage their child's future asthma exacerbations at home. Among those who did not feel confident, three main themes emerged: 1) their child had recently received an asthma diagnosis, and the parents did not feel that they possessed sufficient experience to handle an exacerbation; 2) parents felt that they lacked adequate specific information regarding the treatment of an exacerbation; and 3) parents expressed feeling uneasy or nervous about the responsibility of treating a child who might develop respiratory distress.

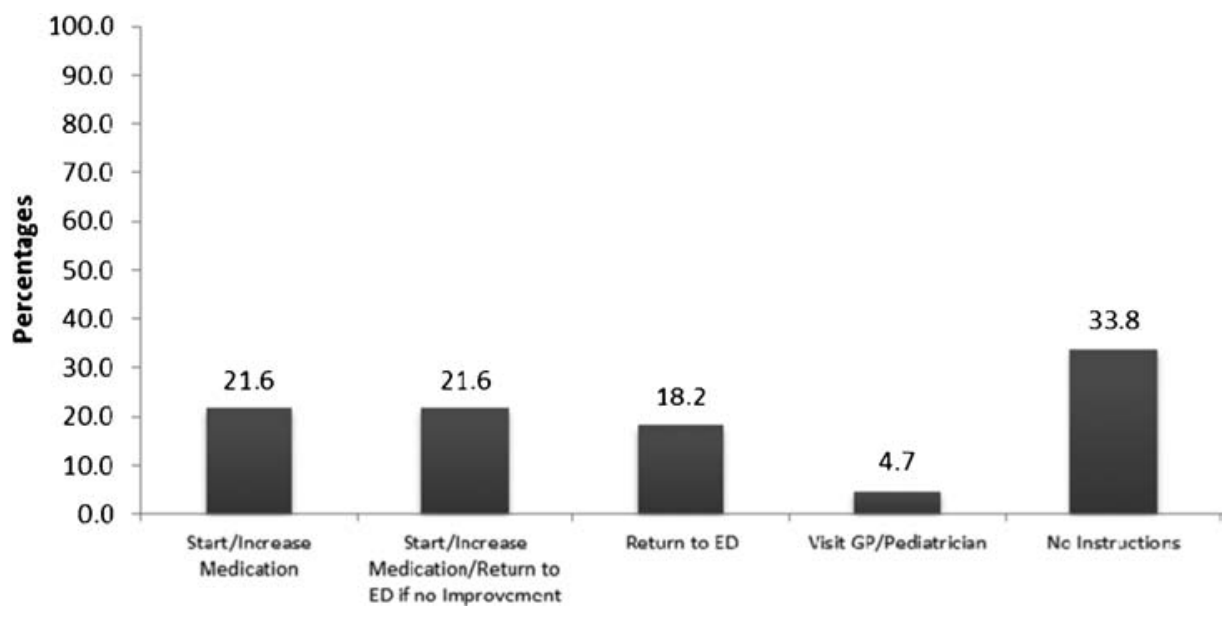

Figure 2. Proportion of parents who report receiving specific instructions by the emergency department (ED) staff on management of future asthma exacerbation. GP = general practitioner. 


\section{Follow-up interview}

Of the initial 148 patients, parents of 133 children were available for a follow-up interview. In the 6-month interval, 52 (40\%) patients had attended the ED at least once more for an asthma exacerbation, $18 \%$ had two or more visits, and $9 \%$ had three or more visits, with URTIs reported as the major trigger. There was no change in the planned strategies for asthma care compared to the first interview.

\section{DISCUSSION}

In this prospective study, most parents of children with asthma recall and implement only a few recommendations that are provided by medical staff at the time of visits for acute care. Recall was poorest about asthma medications, use of inhaler devices, and receiving any asthma-related reading material. Parents remembered more frequently that ED staff provided them with some, although highly variable, directions to manage future exacerbations of their child's asthma. Demonstrating the proper use of inhalers was either not recalled by parents or not done in the ED.

We cannot determine whether these problems result from a lack of parental recall and/or a lack of effective education provided in the ED. The ED in this study used a clinical pathway with a checklist of topics to be covered. Although this pathway "cues" physicians and staff to provide standardized care and education, this likely does not occur for every patient. Parents may receive the recommended education and still fail to recall the key points after the visit. A multicomponent system of follow-up care that relies less on brief interactions with patients in the ED is essential. Effective mechanisms for delivering asthma education and improving follow-up care include written action plans, ${ }^{16,17}$ video-based education, ${ }^{18}$ and postdischarge text messaging. ${ }^{19}$ Additional strategies could include automatic reminder telephone calls to see the family physician, education from the pharmacist, access to online resources, and immediate discharge notes sent to the family physician to alert them of the ED visit.

We found that although most parents recognize URTIs to be the primary trigger of asthma exacerbations in their child, most home strategies reported by parents for improving asthma control were focused on environmental changes such as dust control.
Preventing most URTIs in children with asthma is a formidable challenge given their exposure to respiratory viruses in school and community settings. A more effective approach may be helping parents to better respond to their child's symptoms of a URTI to reduce the likelihood of the URTI progressing to a serious asthma exacerbation warranting an ED visit. The NAEPP guidelines for asthma ${ }^{8}$ and the Global Initiative for Asthma (GINA) guidelines ${ }^{20}$ recommend that children with asthma and a history of severe exacerbations who develop any symptoms of a URTI immediately begin a course of corticosteroids to reduce the likelihood of a severe exacerbation. In the present work, consistent with our clinical experience, this recommendation was not routinely followed. Both health care providers and parents need to implement strategies that address the impact of URTIs on pediatric asthma exacerbations.

Although they expressed confidence in managing their child's asthma exacerbation, parents continued to attend the ED. Many factors likely contribute to this pattern of care. Parents may primarily respond to severe, more immediate exacerbation symptoms and defer medical visits whenever they perceive their child to be well. Regular use of ED services might also become "normalized" for some parents. Emergency staff may reinforce this pattern given our observation that many participants were advised to return to the ED for future exacerbations. Strategies to reduce frequent ED use should focus on providing families with reasonable alternatives to $\mathrm{ED}$ care for mild to moderate exacerbations.

Several limitations are apparent in our study design. Our findings may not necessarily be generalizable to different settings or jurisdictions with different health care delivery or population characteristics. In addition, patient- and parent-reported outcomes are subject to recall bias. Such bias was limited in part by conducting our first interview shortly after the index visit, using structured interviewing methods, and evaluating medical records. Other factors that might influence parental recall were not assessed and may include physician experience, time of the visit, case volume in the ED, parental fatigue, and information provided by other care providers. Nevertheless, parents' retention of key discharge instructions and implementation of asthma care to prevent relapses are poor and reinforce the need to improve at numerous levels. 


\section{CONCLUSIONS}

Parents of children with asthmatic exacerbations recall and implement only a few recommendations from medical staff following visits for asthma care in the ED of a pediatric tertiary care centre. Limitations in asthma education and verbal communication in acute care settings may be amenable to numerous interventions and enhancements, which require further study to define the strategies that improve the postdischarge care of children with asthma who frequently visit the ED. Such interventions could target the prevention and management of asthma exacerbations triggered by URTI. Other targets requiring investigation may be more subtle or complex, including the elements of communication and the relationships between parents, primary care physicians, and ED staff caring for children with asthma, as well as the models of care.

Acknowledgements: Dr. Camp is a Michael Smith Foundation for Health Research Clinical Scholar.

Competing interests: This work was supported in part by an unrestricted educational grant from GlaxoSmithKline Canada. The sponsor did not participate in the study design; the collection, analysis, or interpretation of data; the writing of the report; or the decision to submit the paper for publication.

\section{REFERENCES}

1. Alpern ER, Stanley RM, Gorelick HM, et al. Epidemiology of a pediatric emergency medicine research network: the PECARN Core Data Project. Pediatr Emerg Care 2006;22: 689-99, doi:10.1097/01.pec.0000236830.39194.c0.

2. Akinbami LJ, Moorman JE, Garbe PL, et al. Status of childhood asthma in the United States, 1980-2007. Pediatrics 2009;123(3 Suppl):S131-45, doi:10.1542/peds.2008-2233C.

3. Guttmann A, Zagorski B, Austin PC, et al. Effectiveness of emergency department asthma management strategies on return visits in children: a population-based study. Pediatrics 2007;120:e1402-10, doi:10.1542/peds.2007-0168.

4. Emerman CL, Cydulka RK, Crain EF, et al. Prospective multicenter study of relapse after treatment for acute asthma among children presenting to the emergency department. 7 Pediatr 2001;138:318-24, doi:10.1067/mpd.2001.111320.

5. Ducharme FM, Kramer MS. Relapse following emergency treatment for acute asthma: can it be predicted or prevented? 7 Clin Epidemiol 1993;46:1395-402, doi:10.1016/0895-4356 (93)90139-R.

6. Benito-Fernandez J, Onis-Gonzalez E, Alvarez-Pitti J, et al. Factors associated with short-term clinical outcomes after acute treatment of asthma in a pediatric emergency department. Pediatr Pulmonol 2004;38:123-8, doi:10.1002/ ppul.20031.
7. Babin SM, Burkom HS, Holtry RS, et al. Pediatric patient asthma-related emergency department visits and admissions in Washington, D.C., from 2001-2004 and associations with air quality, socio-economic status, and age group. Environ Health 2007;6:9, doi:10.1186/1476-069X-6-9.

8. Akinbami L, Moorman JE, Liu X. Asthma prevalence, health care use and mortality: United States, 2005-2009. Natl Health Stat Rep 2011;32:1-16.

9. National Heart, Lung and Blood Institute, National Asthma Education and Prevention Program. Expert Panel Report 3: Guidelines for the diagnosis and management of asthma. Bethesda (MD): U.S. Department of Health and Human Services; 2007.

10. Warman KL, Johnson Silver E, McCourt MP, Stein REK. How does home management of asthma exacerbations by parents of inner-city children differ from NHLBI guideline recommendations? Pediatrics 1999;103:422-7, doi:10.1542/ peds.103.2.422.

11. Diette GB, Skinner EA, Markson LE, et al. Consistency of care with national guidelines for children with asthma in managed care. 7 Pediatr 2001;13:59-64.

12. Scarfone RJ, Zorc JJ, Capraro GA. Patient self-management of acute asthma: adherence to national guidelines a decade later. Pediatrics 2001;108:1332-8, doi:10.1542/peds.108.6. 1332.

13. Andrews Al, Teufel RJ, Basco WT. Low rates of controller medication initiation and outpatient follow-up after emergency department visits for asthma. 7 Pediatr 2012;160:32530, doi:10.1016/j.jpeds.2011.07.037.

14. Williams KW, Word C, Streck MR, Titus MO. Parental education on asthma severity in the emergency department and primary care follow-up rates. Clin Pediatr (Phila) 2013 Mar 6. [Epub ahead of print]

15. Norton SP, Pusic MV, Taha F, et al. Effect of a clinical pathway on the hospitalization rates of children with asthma: a prospective study. Arch Dis Child 2007;92:60-6, doi: 10.1136/adc.2006.097287.

16. Emond SD, Reed CR, Graff LI, et al. Asthma education in the emergency department. On behalf of the MARC Investigators. Ann Emerg Med 2000;36:204-11, doi:10.1067/ mem.2000.109168.

17. Ducharme FM, Zemek RL, Chalut D, et al. Written action plan in pediatric emergency room improves asthma prescribing, adherence, and control. Am 7 Respir Crit Care Med 2011;183:195-203. [Epub 2010 Aug 27], doi:10.1164/ rccm.201001-0115OC.

18. Deis JN, Spiro DM, Jenkins CA, et al. Parental knowledge and use of preventive asthma care measures in two pediatric emergency departments. I Asthma 2010;47:551-6, doi:10. 3109/02770900903560225.

19. Macy ML, Davis MM, Clark SJ, Stanley RM. Parental health literacy and asthma education delivery during a visit to a community-based pediatric emergency department: a pilot study. Pediatr Emerg Care 2011;27:469-74, doi:10.1097/ PEC.0b013e31821c98a8.

20. Yun TJ, Arriaga RI. A text message a day keeps the pulmonologist away. In: Proceedings of the Computer Human Interaction, CHI 2013 Human Factors in Computing Systems; April 27 - May 2, 2013; Paris France. Association for Computing Machinery; 2013. p. 1769-78. 